\title{
Being a Man: Rethinking Vulgar Masculinity in Boyz $N$ the Hood
}

https://doi.org/10.3126/litstud v29i01.39594

Bhushan Aryal

\begin{abstract}
In this paper, I analyze the two versions - vulgar and bourgeois - of masculinity offered in the movie Boyz $\mathrm{N}$ the Hcood, and argue that the movie's advocacy of bourgeois masculinity as a solution to the woes facing inner city black communities in the United States is insufficient. Highlighting how masculinity is not an isolated position independent of identity politics such as feminism, I argue that the new conception of masculinity needs a progressive approach that can accommodate feminist and other related interests. While the paper is about the movie, the significance of the argument transcends a particular context: envisioning a progressive form of masculinity is as much the concern of black communities in the U.S. as it is of Nepali communities across the globe.
\end{abstract}

John Singleton's 1991 film Boyz $N$ the Hood represents two versions of black masculinity, and presents bourgeois masculinity as a solution to the problems facing inner city black communities in the United States. The first version of masculinity which most of the black male characters in the film, including Doughboy, embody is presented as pathological because of its structural dependence on violence, alcoholism and sex. The film depicts this form of masculinity as a homicidal, self-destroying male embodiment. The second version, which we will call bourgeois masculinity, comprises the characteristics such as personal responsibility, non-violence and black brotherhood. The characters of Furious Styles, Tre Styles and Ricky represent this form of masculinity as they try to assume more responsible familial and social roles when their environment pushes them against such attempts. Depicting the first form of masculinity as a major affliction in black America, the film prescribes new form of masculinity as a solution to a persistent internal setback, particularly the diminished self-image and role of a black man. While the movie's prescription of black bourgeois masculinity is a significant move for healing familial and cultural woes within black communities, I argue that it is not sufficiently progressive as it reproduces patriarchal social order and male dominant public sphere without addressing feminist voices.

Certainly, connecting black masculinity and other concerns - such as the ones raised by feminism - is not always a welcome gesture. For instance, Robyn Wiegman, while simultaneously acknowledging "the film's overt signs of sexism," thinks that challenging the film's representation of black masculinity from feminist perspective can be problematic as it emerges from a particular historical context (183). Given the gravity of situation in which white racist 
supremacy has designed the feminization and self-destruction of black males, thinking of the effects of the film's black masculinity on feminist projects will undermine "the historicizing gesture that seeks to place [it] in the broader context of cultural production" (Wiegaman 183). Wiegman further states that such approach "risks the inscription of feminist analysis inattentive to the multiplicity and over determining construction of race and gender" (183). Wiegman contends that the state of emergency among the inner city black males should allow fixing its own problem first before dealing with other implications, including its representation of women.

As Wiegman seems to acknowledge, Boyz $N$ the Hood was an achievement for black liberation as it contributes significantly to breaking the Hollywood tradition of "white man's burden." Based on the orientalist tradition that had its roots in philosophes such as Hegel's hierarchy of civilizations, the racist ideology of "white man's burden"-articulated in Rudyard Kipling's 1899 eponymous poem- assumes blacks as naturally juvenile, thus unprepared to take responsibility for their improvement, ultimately assigning messianic race up-lifting responsibility to white brothers. The film certainly finds white superstructure responsible for the crisis in black community in the South Side of LA, but it abstains from suggesting that whites have to come to solve the problems. The usual patronizing white man is absent in the film. It assigns black males the total responsibility of ameliorating their entrenched difficulties. Furious Styles, the edifying father and spokesman for bourgeois masculinity in the film, preaches black brotherhood, disciplined life, and individual responsibility as the surest weapon for breaking the vicious cycle of poverty, crimes and indignity in black neighborhood. Though this restoring of black masculinity is a positive gesture, it does not or should not exempt the film or any serious representation of race-gender dynamics from asking them for a higher goal. Since the film takes "quite seriously and self-consciously their representational role as modeling a future for today's young black men" (Wiegman 173), any limitation in the imagination of emerging black masculinity not only hinders the broader possibilities of such imagination but also allows us to condone the film's misogynist slurs as normal, acceptable facts.

The part of the problem of black masculinity offered by the film stems from a narrow understanding of black problem. It assumes that poverty, crime and disorder in the black communities are the result of the emasculation of black males. From this perspective, racism in the United States is equivalent to the emasculation of black males. The corollary of such assumption is that restoring the masculinity of black males will automatically address the structural racism and other social ills associated to it. From this angle, as Athena D. Mutua theorizes, restoring black masculinity suggests, "providing them [black men] access to jobs and other opportunities that would allow them to be real men, defined by the established order as being in a position to lead, provide for, and to control their environment, including their women and children" (13). As Mutua states further "providing 
black men access to patriarchal privilege was the answer to the oppressed conditions of black communities" (13). Boyz $N$ the Hood falls in the trap of this thinking, without being able to identify the complexity of racism and its nexus with gender and class. Undoubtedly, rampant racism devastated black males and correcting racist social structure needs the restoration of their dignity, responsibility and humanity. But what cannot be the solution is the adoption of same old, vulgar masculinity that is insensitive to the issues raised by women; masculinity is not an independent category free from other elements of macro social structure. Masculinity is automatically implicated with the question of female position in society, and thus emerging form of masculinity should not be conterminous to any form of patriarchy.

What we need is what Mutua calls progressive masculinities. This form of masculinity is based on a bigger dialogue of inclusive democracy as it acknowledges the rights and dignity of all members of society. Mutua defines progressive black masculinities as "unique and innovative practices of the masculine self actively engaged in struggles to transform social structures of domination. Progressive masculinities are committed to liberating others and themselves from these constrains and therefore eschew relations of domination in their personal and public lives" (11). Indeed Mutua's definition is sophisticated as it directly addresses the limitations of vulgar masculinity that is insensitive to women's issues, but her tone here is still not-so-progressive: the phrase "liberating others" assigns patronizing role to African American males, again replicating the patriarchal male-female hierarchy. In another deliberation, Bahati Kuumba links progressive black masculinities with gender justice and women's human rights (228). Since the marginalization and domination of females in patriarchal social structure is directly related to patriarchal version of masculinity, Kuumba thinks that a progressive black masculinity should transcend the limitations of male roles set for patriarchal order so that it can help fight the bigger structure of domination ensuring not just males' rights but also upholding females' dignity and freedom in the process.

Too occupied with the male question as if it were an independent issue, Boyz $N$ the Hood represents women mostly as sex objects-worthy of nothing more. Since the film is about black males, the assumption is that the film has nothing to do with female representation. But the dialogues and interactions automatically reveal the entranced asymmetry of power relations between the two sexes, and the film just overlooks it. The whole atmosphere in the film is misogynist. At one point, Doughboy's girlfriend questions why he and other boys call them bitch in almost every utterance. The answer is just so "normal', "Because you are a bitch." Nothing further happens, as if his answer is a justified clarification. While the film raises this question, it fails to delve deeper suggesting appropriate actions. Even while it presents a successful, independent woman like Reva, who earns master's degree and has decent living, she is deprived of her 
motherhood and the film gives short shrift to her success.

Only two short instances in the film deliberate on the female's role in the construction of masculinity. Tre, after the devastating experience in the hand of a black police man, enters into his girlfriend's room, gets angry, and ultimately bursts into tears. Mindful that a version of masculinity has been infringed, he says, "I never thought I'd be crying in front of a female." Brandi replies, "You can cry in front of me." In another instance, Furious and Reva discuss about their son's future in a restaurant. Reva wants her son, who has been living with his father, to stay with her. Proud of his accomplishment in raising a model son, Furious does not want to handover Tre to Reva. Answering to Furious's argument that she did not care him when he needed her and that now Tre has grown up and can decide on his own, Reva argues, " Of course you took in your son, my son......our son.......and you taught him to be a man. I'll give you that because most men ain't man enough to do what you did. But that gives you no reason, do you hear me, no reason to tell me that I can't be a mother to my son." Though hushed in the violence and sexist atmosphere of the film, Reva's claim of motherhood questions the film's tacit understanding that only responsible fathers can raise their boys. In fact, Reva's further statement that "what you did is no different from what mothers have done from the beginning of time" opens up space for progressive masculinities.

A prominent aspect of masculinity discussed in the film is black fatherhood. Furious teaches his son Tre that just having biological capability of reproducing babies does not make a person a man. A real man, he says, should know raising his boy. So, whole issue of masculinity becomes the cultural production of healthy boys, and assumption is that only males are capable of doing this. The film presents Furious as a successful father and Tre is prepared not to have baby before he is ready to take responsibility for it. In many ways, Furious trains his son to be a different kind of man, a person who would not kill others, would not drink alcohol, and take responsibility for raising his children. Indeed, it is a far better version of masculinity than the one Doughboy practices. And it also holds the potentiality for incorporating other needs of social transformation. But, despite its success on the screen as his son largely embodies his teaching, Furious's fatherhood is not as democratic and progressive as it reproduces the same masculinity that feeds on patriarchal privileges. Instead of questioning the stereotypical roles set for genders, Furious trains another man who will take control of social environment and family. Though Furious raises Tre as a single parent, his regimen of upbringing a child is not thought in terms of child's overall development, but is geared toward making a typical man - not a very progressive move. In the light of feminist movement and its questioning of gender roles, a progressive black fatherhood needs a different kind of mindset. Though it is hard to accurately articulate this form of fatherhood, Mark Anthony Neal thinks that it is some form of "an engaged, nurturing, feminist, and yes, perhaps a progressive black father" (279). Bringing back Reva's comment in the film, it is as much about 
doing what women have been performing for hundreds of years as much as about readjusting the roles in the changed circumstances. Any account of masculinity independent of female aspiration is unrealistic and isolationist in spirit.

The isolationist spirit of masculinity also gets reflected in the way film discusses a black man's relationship with the larger mainstream society. For instance, Furious does not only teach black brotherhood as collective identity for fixing the culture of homicide, but also advocates that the U.S. army is not a place for black man. Undoubtedly, army, like other institutions of establishment, may reflect the racial prejudices prevalent in society. But Furious' wholesale rejection of army originates more from his isolationist philosophy of black brotherhood rather than from the objective analysis of army culture itself. The zealous advocacy of rigid black brotherhood to the point of isolating them from the mainstream institutions leads to another kind of ghettoization. The focus instead should be on reforming mainstream institutions and making them conducive to black aspirations.

Thus, Boyz $N$ the Hood's emphasis on the reformed black masculinities for solving racial problem is critical. But the film's prescription of an isolated, vulgar masculinity does not represent the best available version in the late twentieth century. Black masculinity needs a progressive approach that can embrace mainstream society, uphold more comprehensive notion of fatherhood, and address the issues of inclusive democracy. The new vision of masculinity demands a sensitivity to the bigger questions of gender and sexuality. Being a man is not an isolated incident, but a sustained work in a network of relationships.

\section{Works Cited}

Kuumba, M. Bahati. “Gender Justice: Linking Women's Human Rights and Progressive Black Masculinities." Progressive Black Masculinities. Ed. Athena D. Mutua. New York: Routledge, 2006. 227-241.

Mutua, Athena D. "Introduction: Mapping the Contours of Progressive Masculinities". Progressive Black Masculinities. Ed. Athena D. Mutua. New York: Routledge, 2006. 11-28. Print.

Neal, Mark Anthony. "Bringing up Daddy: A Progressive Black Fatherhood?"

Progressive Black Masculinities. Ed. Athena D. Mutua. New York: Routledge, 2006. 263-280.

Singleton, John, dir. Boyz 'N the Hood. Columbia Pictures, 1991. Film.

Wiegman, Robyn. 'Feminism, 'The Boyz,' and Other Matters Regarding The Male". Screening The Male. Eds. Steve Cohen and Ana Rae Hark. New York: Routledge, 1993. 173-193. Print. 